\title{
Obstructed Hemivagina and Ipsilateral Renal Agenesis (OHVIRA) Syndrome Associated with Bicornuate Uterus with Recurrent Hematopyo-metra with Reactive Thrombocytosis, A Case Report
}

\author{
Kaul Indu', Khalid Shaista ${ }^{2}$, Sharma Sudha ${ }^{3}$ \\ ${ }^{1}$ Professor, Department of Gynecology and Obstetrics, GMC Jammu, J\&K, ${ }^{2}$ Postgraduate Student, Department of Gynecology and Obstetrics, \\ GMC Jammu, ${ }^{3}$ Assistant Professor, Department of Gynecology and Obstetrics, GMC Jammu.
}

\section{A B STRACT}

The development of the female urinary and genital system is deeply linked at the embryological level. About $10 \%$ of infants are born with abnormality of the genitourinary system, and anomalies in one system are often mirrored by anomalies in another system. ${ }^{1}$ The OHVIRA syndrome is a rare set of anomalies affecting the female urogenital tract. The syndrome consists of obstructed hemivagina with ipsilateral renal agenesis with uterine anomalies. The true incidence of the OHVIRA syndrome is not precisely known, but according to the available literature it is estimated between 0.1-3.5percent of all mullerian anomalies. It is mostly reviewed in western literature under pediatric surgery, as the median age of presentation is 12.5 years (birth-25yrs), but in our setup it usually falls into the gynecologists purview as the age of presentation is in early childbearing age. A 22 year old married patient was admitted in our hospital as a referred case of abdominopelvic mass with dysmenorrhea. The patient after complete evaluation was shown to have a uterus bicollis unicornis, with obstructed hemivagina absent right kidney with unilateral right hydrosalpinx and reactive thrombocytosis. Here, we present the diagnostic modalities that helped us reach the diagnosis of this rare syndrome, its associated features and surgical management of an adult patient in a low cost setting.

Key words: Hemivagina, Ipsilateral Renal Agenesis, Hematopyo-metra, Thrombocytosis.

\section{CASE REPORT}

A 22 year old married female non-diabetic, normotensive was referred to us with the chief complaints of amenorrhea 2 months, pain lower abdomen and foul smelling vaginal discharge for 1 month. She was admitted in our hospital on $3^{\text {rd }}$ November 2010. The patient was in her usual state of health 2 months back when she started with pain in her lower abdomen around the expected date of menstruation. The patient had previous history of dysmenorrhea, so she did not seek immediate medical help, the pain was not relieved with medication and it grew in intensity. The patient consulted a local gynecologist who performed a preliminary pregnancy

Address for correspondence:

Dr. Professor Indu Kaul,

House No.1, Sector 1, Channi Himmat, Jammu. 180015.

Ph no: 09419145145

E-mail: indukaulkhoda@gmail.com

DOI: 10.5530/ijmedph.3.2011.13 test which was negative and referred her to our center as a case of pelvic mass with pain . The patient also noticed a foul smelling vaginal discharge which was dark in colour. As per history the patient reached menarche at the age of 14 years. Her cycles were irregular since menarche with scanty flow. Cycles were associated with pain lower abdomen which was colicky in nature, radiating to her back and was relieved with medication. The patient is a nulligravida with married life of 11 months, non-smoker and non-alcoholic with positive history of constipation and dyspareunia. Other medical and surgical history was not significant.

On examination, the patient was conscious, cooperative, well oriented to time, space and person. Her vitals were maintained except for a temperature of $99^{\circ} \mathrm{F}$. She had pallor, chest and CVS examination was unremarkable. Per abdomen the patient had an 18 weeks mass arising out of her pelvis which was dull on percussion, non-tender, tense, symmetrical and its lower margins could not be made out. Per speculum the patient had foul smelling thick blackish discharge and the cervix could not be identified. Per vaginum 
the exact uterus size could not be appreciated, there was bogginess in the anterior vaginal wall.

A working diagnosis of Hematopyometra was made and the patient's investigations were sent. The patient was put on broadspectrum antibiotics and was given two packed cell transfusions. Laboratory findings revealed hemoglobin of $7 \mathrm{~g} / \mathrm{dl}$, TLC $12,000 / \mathrm{mm} 3$. Trans-abdominal sonography demonstrated Bicornuate uterus with Pyometra and right Adenexal mass with absent right Kidney.

An MRI and CT abdomen was planned to delineate the anatomy in greater detail. MRI using T1 and T2 weighted axial, coronal and sagittal images revealed Bicornuate uterus with right Hydrosalpinx with a non-communicating right horn with Hematocolpos on the left side.(Picture 1, $2 \& 3$ ) The left horn was seen communicating with the common cervical canal. Bilateral multiple follicular cysts were present in both the ovaries.

The patient was then planned for laprotomy and as is routine, the patient was subjected to detailed pre-anesthetic

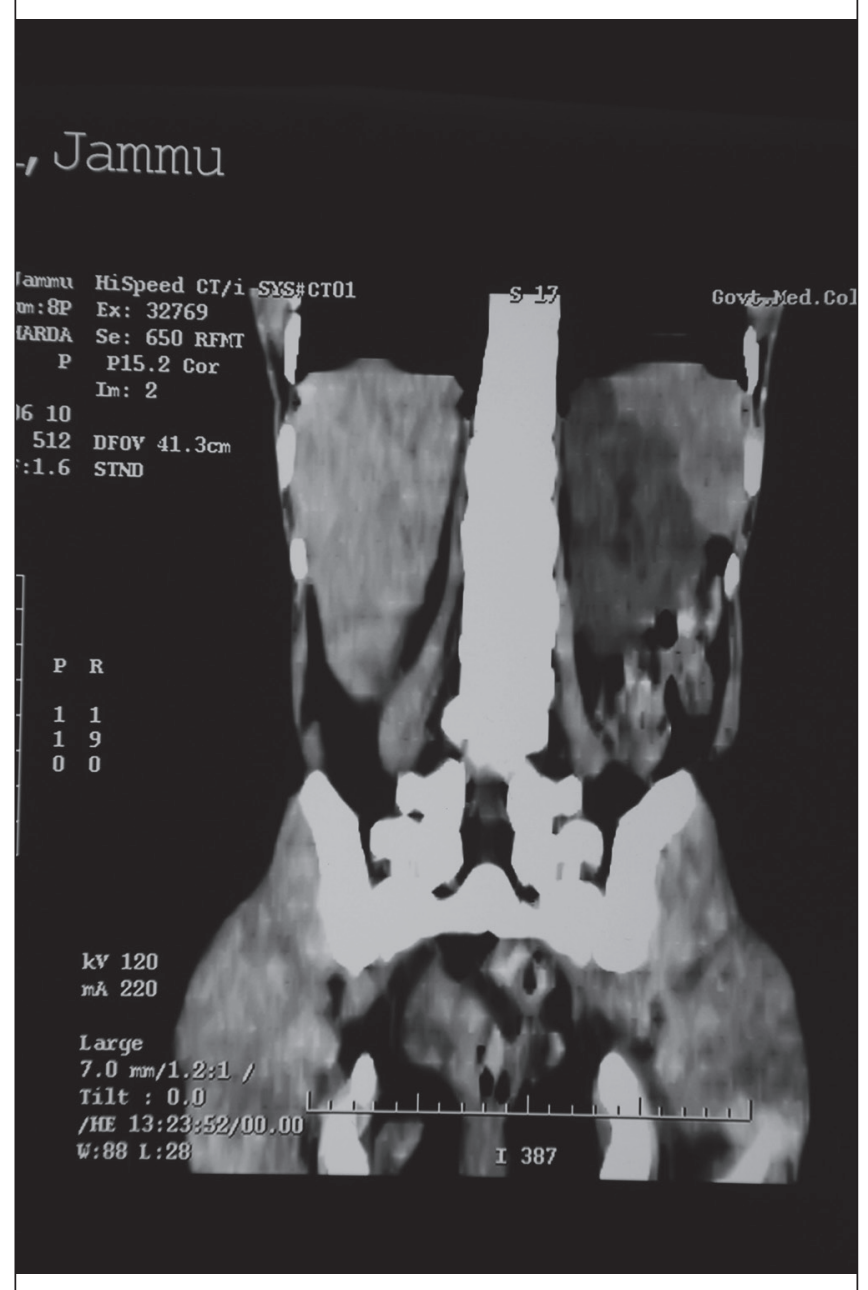

Figure 1 investigations which revealed that the patient had a platelet count of $7 \mathrm{lac} / \mathrm{mm} 3$, other investigations including renal function tests were within normal limits. The patient continued on antibiotics and bone marrow aspiration was done. The bone marrow cytology revealed mild Granulocytic Hyperplasia with Reactive Thrombocytosis with Normoblastic Erythropoesis.

The patient was continued on antibiotics. The patient's platelets showed a decreasing trend and finally the patient was fit for surgery. Before laprotomy, examination under anesthesia was performed. A transverse vaginal septum was found which was excised. A single cervix was identified through which uterine cavity was sounded. The left cavity was found communicating with the cervical canal.

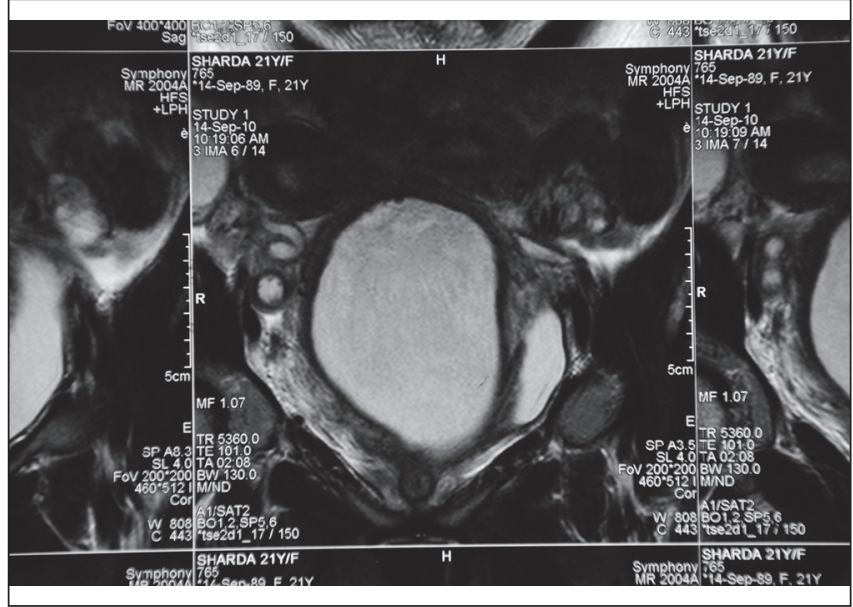

Figure 2

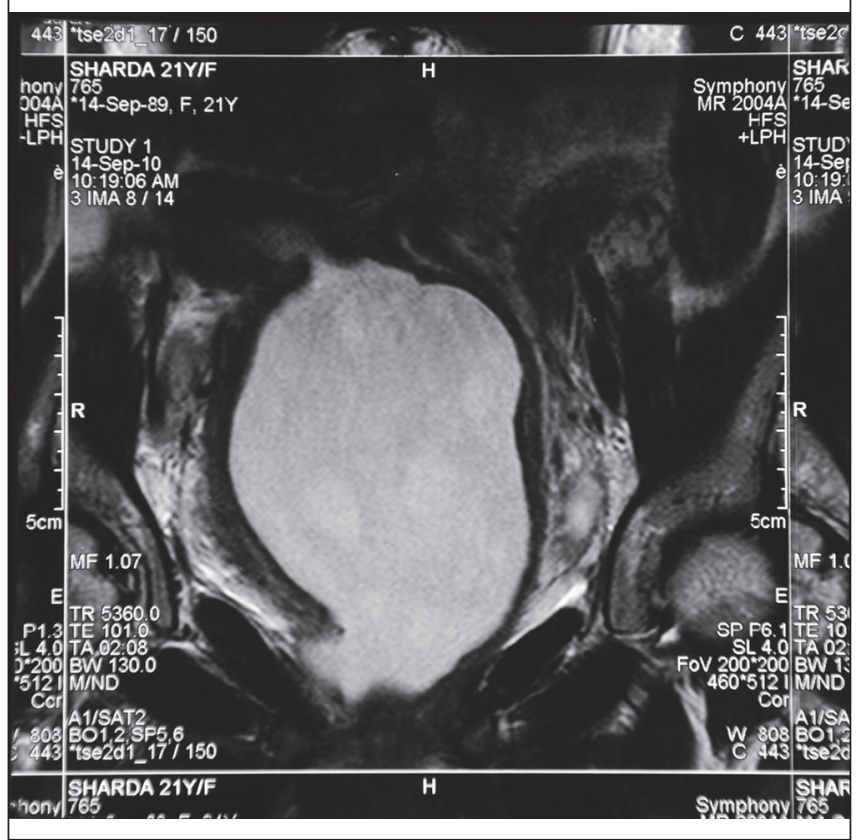

Figure 3 
Intraoperatively a rectovesical ligament was found, separating the two cornua of the uterus, which was excised. (Picture $4 \& 5$ ) To correlate the findings of MRI and Ultrasound a vertical incision was given on the anterior surface of right cornua. The findings of imaging studies were confirmed and non-communicating cornua was seen on the right side with myometrial hyperplasia. The horn was then excised and ipsilateral salpingectomy carried out in view of hydrosalpinx. Ovarian drilling was done in view of the multiple follicular ovarian cysts and keeping in mind her fertility status. An intraabdominal drain was placed, which was removed on the fifth post-operative day. Postoperatively the patient did well on antibiotics and received one more packed cell transfusion. The stitches were removed on the eighth postoperative day.

The patient was discharged on oral progesterone (Norethisterone) to control her cycles and was asked to come for follow up. On follow up the patient came with withdrawal bleeding 1 week after stopping of progesterone with no dysmenorrhea. Currently the patient is doing well and hopeful of a pregnancy.

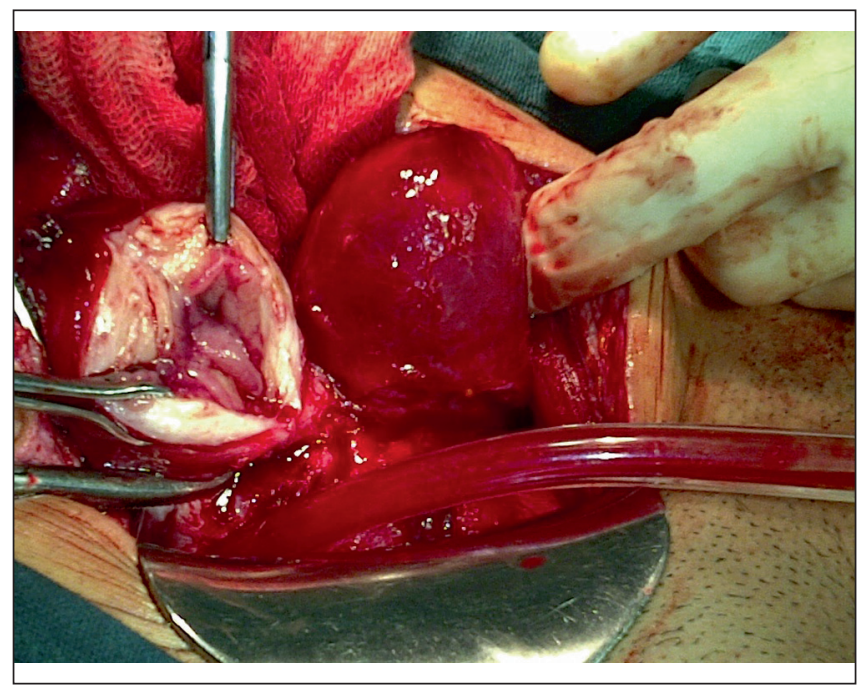

Figure 4

\section{DISCUSSION}

The OHVIRA syndrome was first described in 1922 as Herlyn-Werner-Wunderlich Syndrome. In one study it was quoted that 300 cases of OHVIRA syndrome have been reported since 1922, ${ }^{2}$ emphasizing the need to report adequately diagnosed and managed cases.

OHVIRA syndrome classically occurs in the setting of Uterine Didelphys or, more rarely a Septate uterus. Renal agenesis is the most widely reported urological anomaly. Uterus Didelphys results from fusion failure of Mullerian ducts. A good working classification for Mullerian anomalies was published by Shivaji B. Mane Pankaj Shastri. ${ }^{3}$ It aims at making the surgical management of such cases easier. To our discretion, this classification is better than the other often quoted academic ones, as it points towards the surgical management of such cases

The presentation is around the age of menarche in the western setup, but literature shows a whole spectrum of presentations from Amenorrhea, Infertility, and Chronic per vaginal discharge to pregnancy complications. With

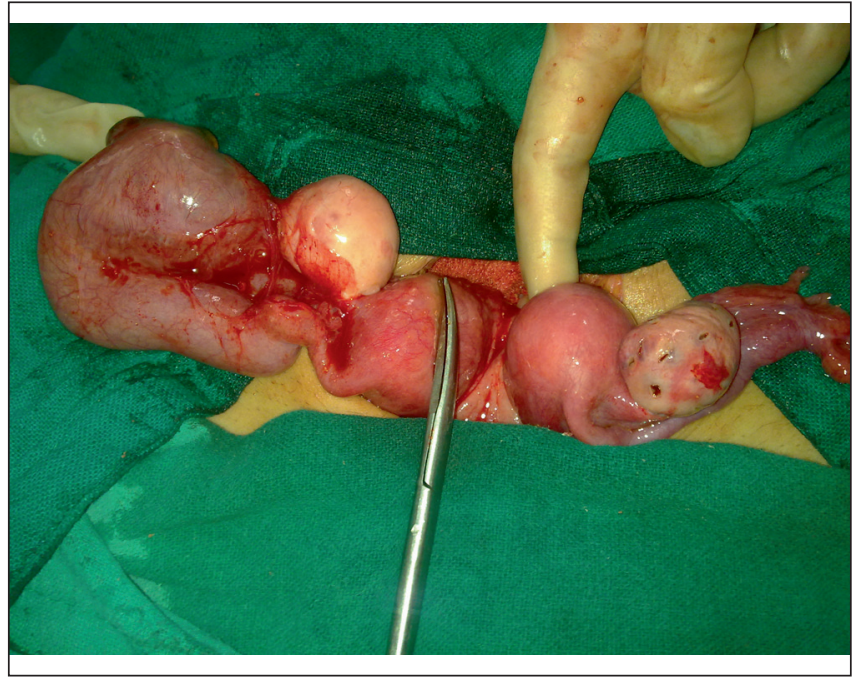

Figure 5

\begin{tabular}{|c|c|c|c|}
\hline Group & Description & Anomaly & Procedure \\
\hline IA & Complete absence of uterus and vagina & Mayer-Rokitansky-Kuster-Hauser (MRKH) syndrome & Bowel vaginoplasty \\
\hline IB & Absence of lower third of vagina & Partial Mullerian agenesis & $\begin{array}{l}\text { Pull-through vaginoplasty } \\
\text { and bowel vaginoplasty }\end{array}$ \\
\hline 2 & $\begin{array}{l}\text { Asymmetric obstructed duplicated } \\
\text { uterus, cervix and vagina }\end{array}$ & Obstructed uterovaginal duplication & $\begin{array}{l}\text { Combined laparotomy and } \\
\text { hysteroscopic treatment }\end{array}$ \\
\hline 3 & $\begin{array}{l}\text { Asymmetric obstructed duplicated } \\
\text { uterus and cervix with single vagina }\end{array}$ & Cervical atresia & $\begin{array}{l}\text { Combined hysteroscopic } \\
\text { and laparoscopic treatment }\end{array}$ \\
\hline 4 & Active Mullerian remnant in ARM patient & ARM with uterovaginal anomalies & $\begin{array}{l}\text { Vaginal replacement and } \\
\text { anterior sagittal } \\
\text { anorectoplasty }\end{array}$ \\
\hline
\end{tabular}


the advent of various imaging modalities the diagnosis has become simplified but the discretion of the treating surgeon is still the most reliable tool.

The surgical management currently favours a single stage procedure with fertility conserving methods. ${ }^{4}$ Literature exists in favour of novel percutaneous procedures such as Percutaneous obstructed hemivagina access (POHVA) to the difficult obstructed hemivagina in the OHVIRA syndrome.

Our setup limits the options like POHVA which we can offer to these patients. However the end point that the patient leads a relatively morbidity free life is ensured with our kind of management. The optimal approach is still adolescent screening for mullerian defects. But, this approach can only be feasible when the adolescent clinics shall be operational in our country. Suad Gholoum, Promod S. puligandla et $\mathrm{al}^{5}$ in one of the largest reviews of OHVIRA/HWWS reported the median age of presentation as 13years.

Our patient presented at 22 years of age and her disease had advanced to hydrosalpinx and may have landed her in Septicemia if not intercepted. Her other complaint was naturally a concern for her fertility, and it has been reported by Sarac A, Demir MK $^{6}$ that $\mathbf{H W W S}$ is a rare cause of infertility. For the radiological diagnosis, a multimodality approach seems to work best. Boram Han, MD, Christopher $\mathrm{N}$. Herndon, $\mathrm{MD}$ et $\mathrm{al}^{7}$ published the first ever case report where transabdominal ultrasound, CECT and MRI were performed in a single patient. Similar studies were done by us and helped lead us to the final diagnosis. But, in our opinion the variants of mullerian defects are many, as is exemplified by the presence of a non-communicating horn of the bicornuate uterus in this case. Thus, the discretion of the treating physician is very important to reach at the final diagnosis. The predilection of right sided anomalies has also been reported ${ }^{8}$ and studies done on animal models attribute this to the right side being more susceptible to hypoxic damage (perhaps the precocious development of mitochondria on the left side of the embryo results in higher energy reserves and less tissue damage due to hypoxia) $)^{9}$ Laparoscopy has been mentioned in the literature ${ }^{10}$ as the procedure of choice when surgery is being considered. But as stated earlier, the low cost setting limited our access to operative laparoscope. Open surgery is also justified in our case in view of the extent of disease. The combined abdomino-perineal approach aims at preserving the patient's fertility. Similar conservative approach has been advocated by TSUCHIYA TAKEHIKO (Teikyo Univ., Mizonokuchi Hosp.) et $\mathrm{al}^{11}$ where they recommend fertility preservation whenever possible. The outcomes of pregnancy in these patients reveal $87 \%$ go on to have a successful pregnancy, while abortions occur in $23 \%$ of the patients, $15 \%$ have preterm births, and $62 \%$ have full-term pregnancies and uncomplicated deliveries. ${ }^{12}$

\section{REFERENCES}

1. Vaughan ED Jr, Middleton GW. Pertinent genitourinary embryology: review for the practicing urologist. Urology 1975;139-149.

2. M.H. Hollander, M.D., P.V. Verdonk, K. Trap Journal of Pediatric and adolescent Gynecology- Vol 21, issue 3, (June 2008) Page 151-153.

3. Shivaji B. Mane, Pankaj Shastri, Nitin P. Dhende, Abu Obaidah and Himanshu Acharya, et al. Our 10-year experience of variable mullerian anomalies and its management, Pedatric surgery International (2010) Vol.26: No.8, Page 795-800 DOI 10.1007/s00383-010-2640-3.

4. Smith NA, Laufer MR. Obstructed hemivagina and ipsilateral renal anomaly syndrome: management and follow-up. Fertil Steril 2007 Apr;87(4):918-22.

5. Gholoum S, Puligandla PS, Hui T, Su W, Quiros E, Laberge JM. Management and outcome of patients with combined vaginal septum, bifid uterus, and ipsilateral renal agenesis (Herlyn-Werner-Wunderlich syndrome). J Pediatr Surg 2006 May; Vol 41 Number 5: Page 987-92.

6. Sarac A, Demir MK. Herlyn-Werner-Wunderlich syndrome: a rare cause of infertility Eur Radiol. 2009 May; Vol 19, numbe r 5: Page1306-8. Epub 2009 Apr 1.

7. Boram Han, MD, Christopher N. Herndon, MD, Mitchell P. Rosen, MD, Z. Jane Wang, MD, and Heike Daldrup-Link, MD, PhD Uterine didelphys associated with obstructed hemivagina and ipsilateral renal anomaly (OHVIRA) syndrome Radiology Case Reports, Vol 5, No 1 (2010) (ONLINE) 2010;5:327.

8. Vercellini P, Daguati R, Somigliana E, Viganò P, Lanzani A, Fedele L. Asymmetric lateral distribution of obstructed hemivagina and renal agenesis in women with uterus didelphys: institutional case series and a systematic literature review. Fertil Steril 2007; Vol. 87: Page 719-24.

9. Fantel AG, Person RE, Burroughs-Gleim C, Shepard TH Juchau MR, Mackler B. Asymmetric development of mitochondrial activity in rat embryos as a determinant of the defect patterns induced by exposure to hypoxia, hyperoxia, and redox cyclers in vitro. Teratology 1991; 44:355-62.

10. Zurawin RK, Dietrich JE, Heard MJ, Edwards CL. Didelphic uterus and obstructed hemivagina with renal agenesis: case report and review of the literature. J Pediatr Adolesc Gynecol 2004; 17:137-41.

11. TSUCHIYA TAKEHIKO, TORIYA YOKO, KAKINUMA SABURO, FUSE YOJI, NAGAE TAKESHI, OKADA AKIKO. A Case Report of Herlyn-Werner Syndrome. Acta Obstetrica et Gynaecologica Japonica VOL.52; NO.10; PAGE 1473-1476(2000).

12. Candiani GB, Fedele L, Candiani M. Double uterus, blind hemivagina, and ipsilateral renal agenesis: 36 cases and longterm follow-up. Obstet Gynecol 1997;90:26-32. 